\title{
Simulasi Bisnis Virtual Pada SMK Budi Mulia
}

\author{
Pipin Farida Ariyani ${ }^{1}$ \\ Universitas Budi Luhur, pipin.faridaariyani@budiluhur.ac.id \\ Titin Fatimah ${ }^{2}$ \\ Universitas Budi Luhur, titin.fatimah@budiluhur.ac.id \\ Atik Ariesta $^{3}$ \\ Universitas Budi Luhur, atik.ariesta@budiluhur.ac.id
}

\begin{abstract}
Abstrak
Kegiatan pelatihan pengenalan dan eksplorasi sebuah perusahaan dengan simulasi bisnis virtual melalui game Enterprise Resource Planning (ERP) bertujuan untuk memberikan pengetahuan dan pengalaman proses bisnis kepada siswa SMK Budi Mulia. Dengan memanfaatkan game simulasi MonsoonSIM dalam membangun dan mengelola sebuah perusahaan virtual, siswa akan belajar mengenai proses bisnis perusahaan. Kegiatan ini diikuti oleh 18 orang peserta yang terdiri dari siswa SMK Budi Mulia dari Bidang Keahlian Bisnis dan Manajemen. Peserta dibagi menjadi 4 tim, dimana dalam permainan, setiap tim merupakan perusahaan virtual yang bersaing memperebutkan pasar dengan perputaran waktu virtual. Kegiatan ini dilaksanakan dengan metode workshop dalam bentuk tutorial, simulasi dan praktik, diskusi, dan evaluasi untuk mengetahui tingkat penyerapan materi pelatihan yang diberikan.
\end{abstract}

Kata Kunci: ERP, simulasi, game, MonsoonSIM

\begin{abstract}
The introduction and exploration training activities of a company with virtual business simulations through the Enterprise Resource Planning (ERP) game aim to provide business process knowledge and experience to SMK Budi Mulia students. By utilizing the MonsoonSIM simulation game in building and managing a virtual company, students will learn about the company's business processes. This activity was attended by 18 participants consisting of SMK Budi Mulia students from the Field of Business and Management Expertise. Participants are divided into 4 teams, wherein the game, each team is a virtual company that competes for the market with a virtual time cycle. This activity is carried out with workshop methods in the form of tutorials, simulations and practices, discussions, and evaluations to find out the participants level of achievement.
\end{abstract}

Keywords: ERP, simulation, game, MonsoonSIM

\section{Pendahuluan}

Selama ini tingkat keterserapan lulusan SMK di dunia kerja masih rendah. Badan Pusat Statistik (BPS) mencatat Tingkat Pengangguran Terbuka (TPT) untuk Sekolah Menengah Kejuruan (SMK) masih tertinggi diantara tingkat pendidikan lain, yaitu 
sebesar 8,63 persen pada Februari 2019 (BPS, 2019). Diperlukan pelatihan kerja bagi siswa agar dunia kerja siap untuk menyerap langsung siswa SMK.

Pemanfaatan teknologi informasi dalam pembelajaran dapat menjadi sistem pembelajaran mandiri (instructor independent). Model pembelajaran yang kini menjadi perhatian dunia pendidikan adalah yang berbasis komputer (computer based instruction). Komputer bukan hanya digunakan untuk menyajikan materi instruksional, tetapi juga bisa untuk memperagakan kejadian dalam kehidupan nyata, dimana setiap pemain memegang suatu peran tertentu, yang melibatkannya dalam suatu interaksi dengan orang lain, yang biasa disebut permainan simulasi (Canta, 2018).

Kegiatan pengabdian kepada masyarakat berupa simulasi bisnis virtual ini dilakukan dengan tujuan untuk memberikan pengetahuan kepada siswa SMK dalam mengenal proses bisnis dan mengelola perusahaan, sehingga memberikan manfaat berupa pengalaman dan pelatihan kerja khususnya dalam mengelola perusahaan. Simulasi bisnis virtual dilakukan dengan memanfaatkan aplikasi game simulasi MonsoonSIM. MonsoonSIM adalah platform pedagogis yang unik dan mendukung experimental learning sehingga siswa dapat mengeksplorasi konsep bisnis dengan game simulasi (Jonathan dan Laik, 2019).

Pelatihan simulasi bisnis menggunakan MonsoonSIM yang dilakukan oleh pengabdi sebelumnya telah memberikan hasil positif pada peserta yaitu peserta dapat mengelola sebuah perusahaan termasuk sumber dayanya, melakukan analisa jangka panjang untuk perusahaan, dan dapat menganalisis kebutuhan pasar dan kompetitor (Sakti dkk, 2019). Game simulasi juga dapat memotivasi siswa melalui materi yang diberikan sesuai kurikulum, sehingga tercipta adanya umpan balik langsung yang diterima oleh siswa (Findawati, dkk).

Konsep yang dicakup oleh MonsoonSIM meliputi: (Monsoon, 2011)

1. Dasar-dasar bisnis dan ekonomi

2. Manajemen operasional bisnis

3. Enterprise Resource Planning (ERP)

4. Logistics and Supply Chain Management (SCM)

Ini adalah konsep penting dan mendasar yang berlaku untuk perdagangan, distribusi, eCommerce, manufaktur, dan bisnis layanan apa pun.

\section{Metode}

Metode yang digunakan pada kegiatan pengabdian kepada masyarakat ini adalah dengan memberikan game simulasi menggunakan aplikasi Cloud Base System yang dilakukan melalui laman monsoonsim.com. Dimana enjoyment of use merupakan faktor utama dalam bermain game simulasi bisnis ini. (Yatim dkk, 2018)

Peserta dibagi menjadi 4 tim yang masing-masing tim terdiri dari 4-5 orang. Setiap tim akan mengelola perusahaan virtual yang bersaing memperebutkan pasar dengan perputaran waktu virtual.

Tahap-tahap yang dilakukan dalam pelaksanaan kegiatan ini adalah sebagai berikut:

1. Tahap Pendahuluan

Mempersiapkan registrasi peserta pada laman monsoonsim.com

2. Tahap Pelaksanaan 
Memberikan pemaparan materi yaitu: (Monsoon, 2011)

a. Pengenalan Enterprise Resource Planning (ERP)

Memberikan penjelasan mengenai ERP dan pentingnya ERP dalam sebuah perusahaan.

b. Pengenalan Game Simulasi MonsoonSIM

Memberikan penjelasan mengenai bagian-bagian modul game simulasi MonsoonSIM.

c. Pengenalan Modul Finance

Memberikan penjelasan tentang kegiatan yang terjadi pada bagian Finance di dalam sebuah perusahaan mulai dari biaya yang dikeluarkan hingga pendapatan perusahaan.

d. Pengenalan Modul Procurement

Memberikan penjelasan tentang proses pembelian barang yang akan dijual, mulai dari pembelian finish good (barang jadi) hingga raw material (bahan mentah) dengan menggunakan jenis-jenis pembelian yang dapat digunakan mulai dari pembelian standar (immediete delivery), pembelian dengan barang yang dikirim sesuai dengan jadwal yang ditentukan (future delivery), hingga pembelian dengan barang yang dikirim sesuai dengan ketentuan waktu dan jumlahnya (blanket po).

e. Pengenalan Modul Retail

Memberikan penjelasan tentang proses penjualan barang pada retail yang ada, mulai dari menentukan harga jual, menentukan luas toko retail, dan melihat laporan penjualan pada setiap toko dan setiap produk.

f. Pengenalan Modul Warehouse

Memberikan penjelasan kegiatan yang terjadi pada gudang mulai dari pengisian barang ke gudang. Pengiriman barang dari gudang ke retail baik yang terjadwal maupun tidak, serta menentukan luas gudang yang diperlukan.

g. Pengenalan Modul Production

Memberikan penjelasan kegiatan yang terjadi pada bagian produksi mulai dari membeli mesin yang akan digunakan, menentukan urutan produksi pada setiap mesin, serta melihat kapasitas produksi mesin setiap harinya.

3. Tahap Evaluasi

Evaluasi kegiatan dilakukan menggunakan Scoring Matrix yang sudah ditentukan KPI-nya untuk mendapatkan tim dengan kinerja yang baik. Nilai matrik yang digunakan untuk penilaian adalah sebagai berikut: (Monsoon, 2011)

a. Sales Retail (High) bernilai $10 \%$

b. Sales Revenue (High) bernilai $10 \%$

c. Market Share - Unit Sold - Retail (High) bernilai 10\%

d. Market Share - Sales - Retail (High) bernilai 10\%

e. Retail Stockout (Low) bernilai 10\%

f. Profit Margin (High) bernilai 10\%

g. Utilization - Retail Space (High) bernilai $10 \%$

h. Cash On Hand (High) bernilai 10\%

i. Net Profit (High) bernilai $10 \%$ 


\section{Hasil dan Pembahasan}

Kegiatan pengabdian kepada masyarakat ini dilaksanakan pada tanggal 6 Agustus 2019, bertempat di Laboratorium Komputer SMK Budi Mulia, dan diikuti oleh 18 orang peserta yang terdiri dari siswa SMK Budi Mulia dari Bidang Keahlian Bisnis dan Manajemen. Pelaksanaan kegiatan pengabdian kepada masyarakat ini dibagi menjadi 5 sesi. Pada sesi pertama, peserta diberikan materi mengenai pentingnya Enterprise Resource Planing (ERP) dalam suatu perusahaan. Pada sesi kedua, peserta melakukan registrasi pada aplikasi game simulasi MonsoonSIM melalui laman monsoonsim.com dan membentuk tim yang terdiri dari 4-5 orang per tim.

Setiap tim mempunyai sebuah perusahaan yang bergerak di bidang penjualan minuman. Setiap perusahaan diberikan modal berupa 3 buah toko dengan luas masing-masing toko $100 \mathrm{~m}^{2}$, produk jadi jus apel 10.000 unit/toko, produk jadi jus jeruk 10.000 unit/toko, dan produk jadi jus melon 10.000 unit/toko. Setiap perusahaan diberikan kondisi awal yang sama mengenai stok awal, dimensi produk, harga produk jadi, harga produk mentah, harga jual awal produk, luas awal toko, biaya sewa toko, biaya overflow toko, area awal gudang, biaya sewa gudang, biaya overflow gudang, biaya pengiriman gudang ke toko, biaya pengiriman berdasarkan jarak, dan biaya per pengiriman. Dari kondisi dan modal awal perusahaan, para peserta belajar mengatur stategi penjualan dan stocking produk untuk bisa meningkatkan penjualan dan mendapat keuntungan yang banyak.

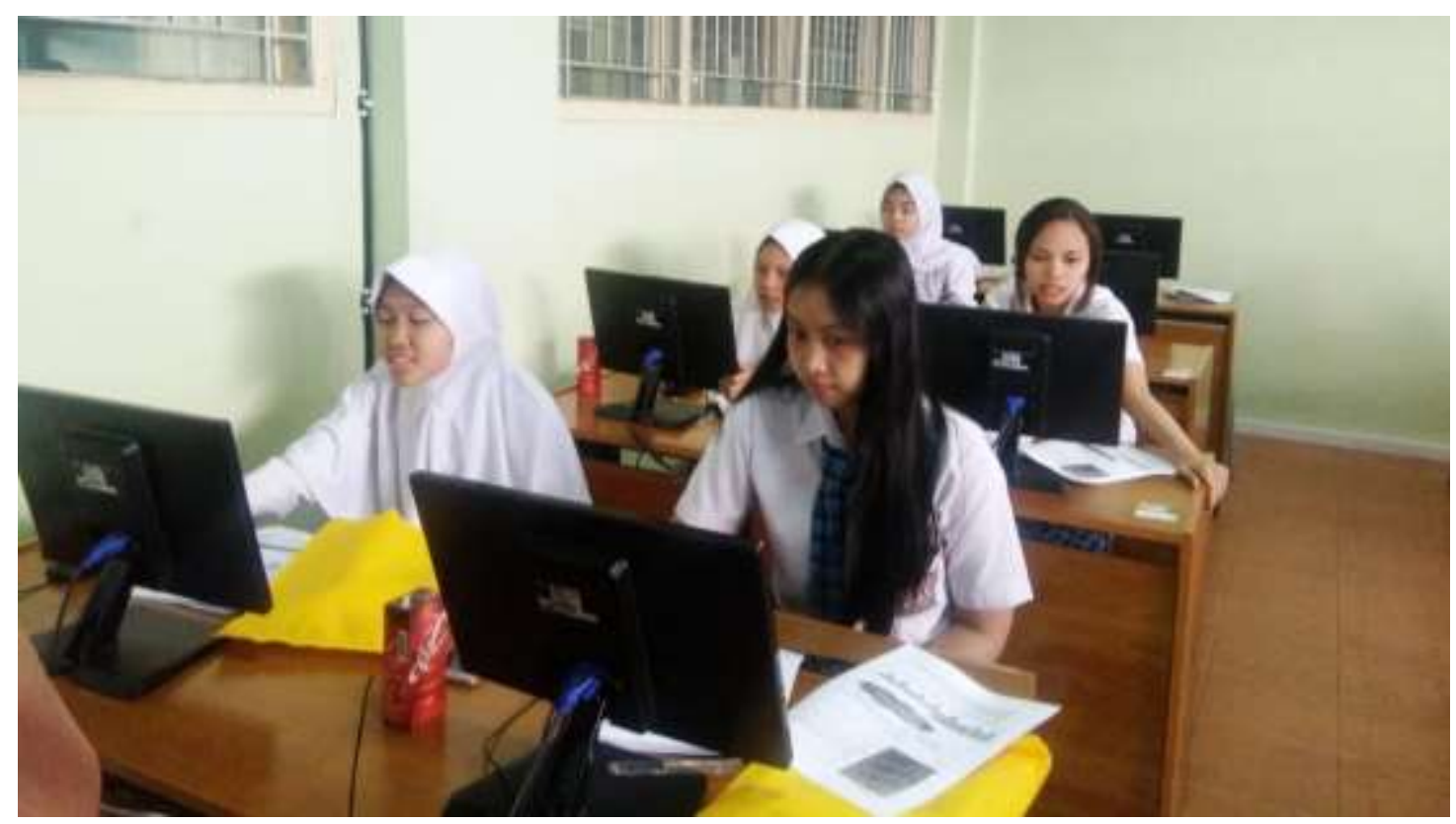

Gambar.1 Suasana pelatihan 1

Pada sesi ketiga, peserta diberikan materi modul finance, procurement, dan retail dari game simulasi MonsoonSIM beserta contohnya. Kemudian simulasi pertama dilakukan dengan waktu permainan selama 18 hari virtual (1 hari virtual sama dengan 30 detik) atau selama 9 menit. 
Penyampaian materi modul warehouse dan production dari game simulasi MonsoonSIM dilakukan pada sesi keempat. Dilanjutkan dengan simulasi kedua selama 18 hari virtual.

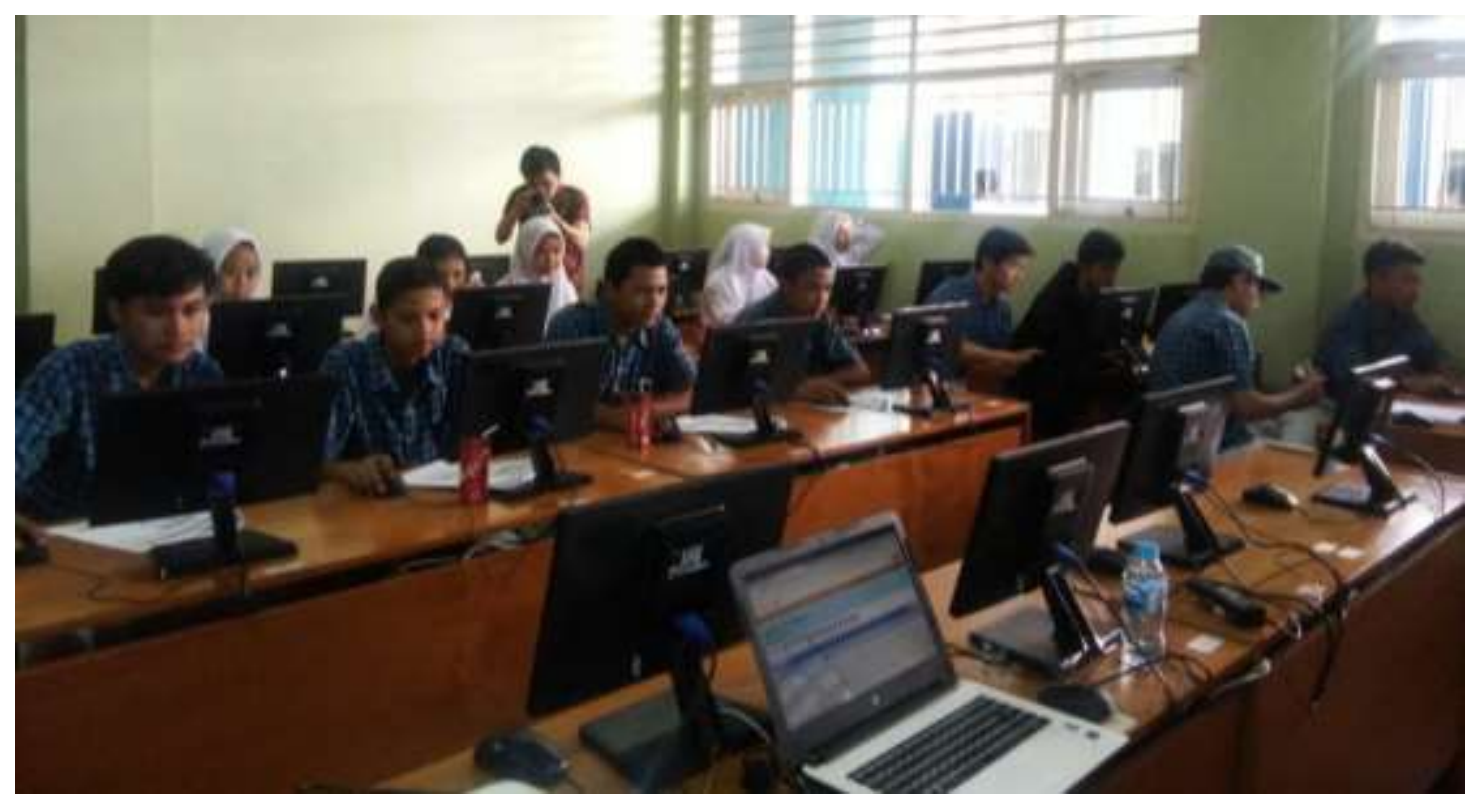

Gambar.2 Suasana pelatihan 2

Pada sesi kelima, peserta melakukan simulasi ketiga selama 120 hari virtual atau selama 60 menit. Simulasi ketiga ini melatih pemahaman peserta akan 5 modul yang telah diberikan yaitu modul finance, procurement, retail, warehouse, dan production. Para peserta bersaing untuk menjadi tim yang terbaik. Secara umum peserta dapat mengikuti pelatihan dengan baik dilihat dari praktek dari materi yang telah diberikan.

Di akhir kegiatan, pelaksana kegiatan pengabdian kepada masyarakat memberikan penghargaan kepada tim terbaik yang dinilai berdasarkan 9 penilaian matrik yang dilakukan pada simulasi ketiga.

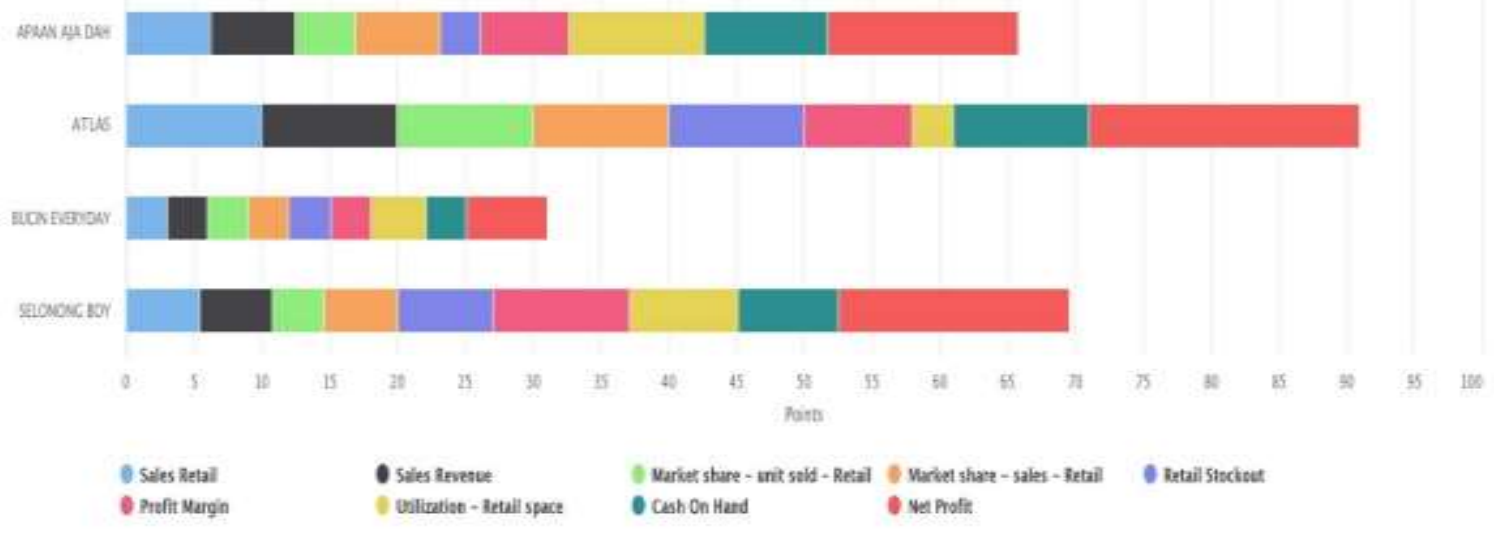

Gambar.3 Grafik Scoring Matrix 
Gambar 3 menunjukkan grafik dari penilaian matrik masing-masing tim yang terdiri dari sales retail, sales revenue, market share - unit sold - retail, market share - sales retail, retail stockout, profit margin, utilization - retail space, cash on hand, dan net profit. Untuk nilai matrik yang diperoleh masing-masing tim ditunjukkan pada Gambar 4.

\begin{tabular}{|c|c|c|c|c|c|c|c|c|c|c|}
\hline Testa & 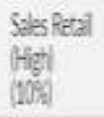 & $\begin{array}{l}\text { Sales Rerenve } \\
\text { Hight) } \\
\text { (100\%) }\end{array}$ & $\begin{array}{l}\text { Market share- unt sold- } \\
\text { Retali| Higt| } \\
\text { (10\%) }\end{array}$ & 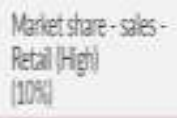 & 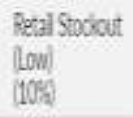 & 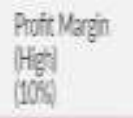 & 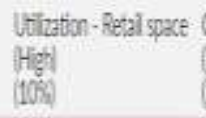 & $\begin{array}{l}\text { Cast On thad } \\
\text { Higl } \\
\text { (10\%) }\end{array}$ & 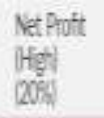 & TOTAL \\
\hline ATLS & 10 & 10 & 10 & 10 & 10 & 8 & 3 & 10 & 20 & 9 \\
\hline $\begin{array}{l}\text { SEONONG } \\
\text { BOF }\end{array}$ & 541 & 541 & 38 & 543 & 796 & 10 & 8 & 7.42 & 1701 & 6954 \\
\hline $\begin{array}{l}\text { APANALA } \\
\text { DHH }\end{array}$ & 624 & 624 & 443 & 624 & 3 & 6.5 & 10 & 9.14 & 1399 & 6578 \\
\hline $\begin{array}{l}\text { BUCN } \\
\text { EVENOHY }\end{array}$ & 3 & 3 & 3 & 3 & 309 & 3 & 4 & 3 & 6 & 3109 \\
\hline
\end{tabular}

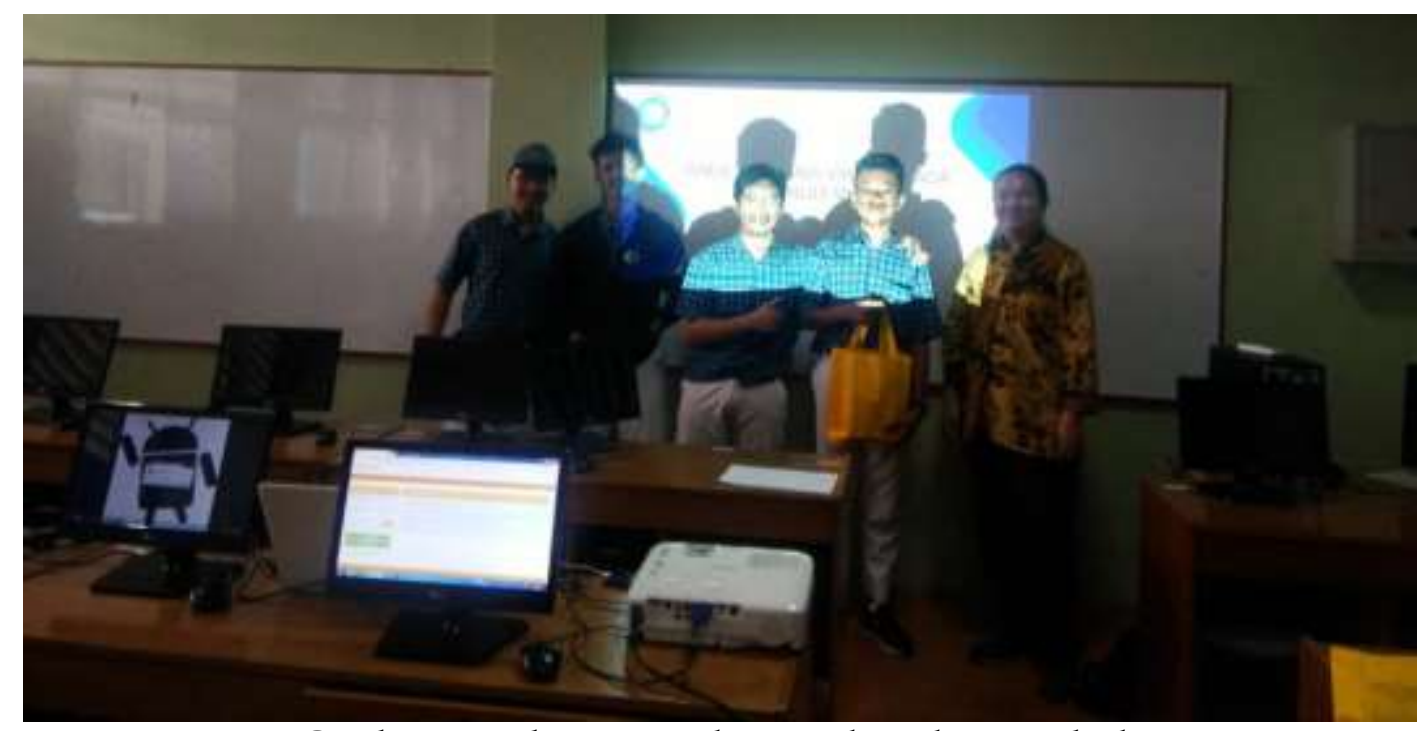

Gambar.5 Pemberian penghargaan kepada tim terbaik

\section{Simpulan dan Rekomendasi}

Untuk mempersiapkan peserta didik dalam berkompetisi di dunia kerja, SMK Budi Mulia berkomitmen untuk memberikan pembekalan ilmu-ilmu yang berorientasi pada praktik sesuai dengan bidang keahliannya. Peserta didik SMK Budi Mulia diharapkan mampu mengimplementasikan ilmu yang didapat pada dunia kerja sesuai dengan bidang keahlian yang dijalani.

Kegiatan pelatihan simulasi bisnis virtual ini telah memberikan pengalaman kepada siswa SMK Budi Mulia dalam mengelola finance, procurement, retail, warehouse, dan production pada suatu perusahaan dengan menggunakan aplikasi cloud base system yaitu game simulasi MonsoonSIM.

Selebihnya diperlukan bentuk kerjasama yang kokoh antara SMK Budi Mulia dengan dunia usaha dan industri atau bahkan dengan perguruan tinggi yang lainnya. Sehingga SMK Budi Mulia dapat menjadi pencetak tenaga kerja siap pakai. 


\section{Daftar Pustaka}

Badan Pusat Statistik. (2019). Berita Resmi Statistik. http://www.bps.go.id [diakses tanggal 31 Oktober 2019]

Canta, D.S. (2018). Implementasi Game Simulasi Pada Mata Pelajaran Keterampilan Komputer dan Pengelolaan Informasi Jurusan Teknik Komputer Jaringan Semester 1 Kelas XI SMK Bina Prestasi Balikpapan. Jurnal Sistem Informasi Vol.1 No.2.

Findawati, Y., Suprianto, Sumarmi, W. (2015). Game Simulasi Wirausaha Berbasis Model Pembelajaran Eksperiensial Sebagai Alternatif Media Pembelajaran di SMK Kelas XI. Jurnal Teknologi Informasi dan Ilmu Komputer Vol.2 No.1.

Jonathan, L.Y., dan Laik, M.N. (2019). Using Experimential Learning Theory to Improve Teaching and Learning in Higher Education. European Journal of Social Science Education and Research Vol.6 No.1.

Monsoon Academy. (2011). What is MonsoonSIM. http://www.monsoonsim.com [diakses tanggal 7 Agustus 2019]

Sakti, D.V.S.Y., Waluyo, S., Fajarita, L., Ferdiansyah, Juanita, S. (2019). Peningkatan Kemampuan Pelajar pada SMK Telkom Jakarta dalam Perencanaan dan Pengembangan Bisnis melalui Pelatihan Simulasi Bisnis Menggunakan Aplikasi MonsoonSIM. Prosiding Seminar Nasional Multidisiplin Ilmu UNISBANK.

Yatim, S.M., Goh, C.F., Mohamad, R.Z. (2018). Factors Influencing Use of Monsoonsim Business Simulation by UTM Undergraduate Students. International Journal of Learning and Development Vol.8 No.2. 